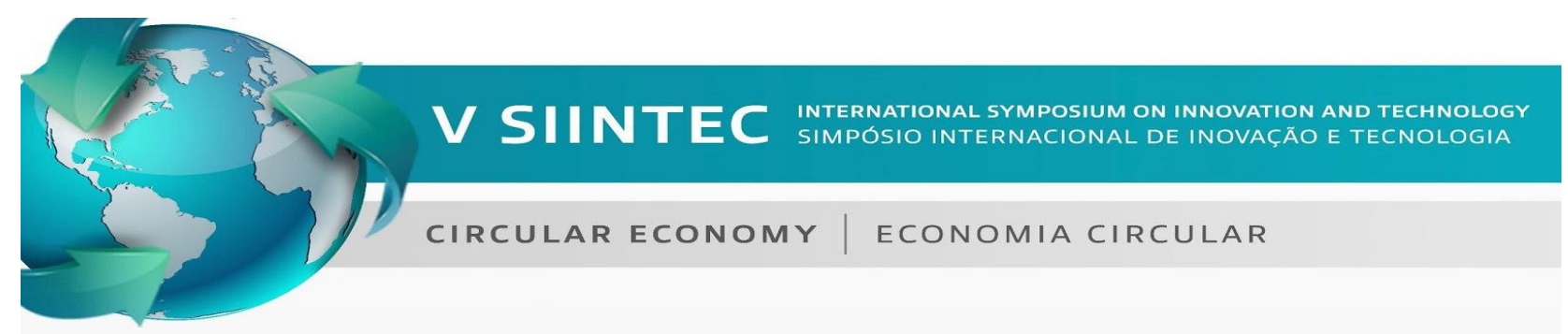

\title{
ESTUDO ERGONÔMICO APLICADO À UM MINI BAJA
}

Rafael de Sena Souza' rafaelsenasouza@hotmail.com; Leo Guedes Blanco² leoguedesblanco@gmail.com; Marcos Antônio Neves Mesquita Filho ${ }^{3}$ marcosmesquita37@gmail.com; Pedro Bancillon Ventin Muniz ${ }^{4}$ pedro.muniz@fieb.org.br

${ }^{1}$ Centro Universitário SENAI CIMATEC - Av. Orlando Gomes, 1845 - Piatã, Salvador - BA, 41650-010; rafaelsenasouza@hotmail.com

RESUMO: Estudos ergonômicos são úteis em todo e qualquer projeto que envolva a interação de pessoas com objetos e sistemas, sejam eles quais forem. Em um projeto mini Baja, por exemplo, o viés ergonômico é muito presente, visto que qualquer complicação neste pode ocasionar problemas de curto a longo prazo, chegando até mesmo a atrapalhar o rendimento da equipe em competições, portanto, busca-se, através de métodos como a utilização de softwares e de materiais adequados, como espumas e apoios de perna, validar um projeto eficaz ergonomicamente. Neste estudo, buscou-se apresentar os métodos utilizados e resultados obtidos em um projeto para garantir a melhor ergonomia possível para o projeto 2019.

Palavras-Chave: Ergonomia; Sistemas Baja; Projeto; Competições.

\section{ERGONOMIC STUDY APPLIED TO A MINI BAJA SAE}

ABSTRACT: Ergonomic studies are useful in all and any project that involves the interaction of people with systems and objects, whatever they may be. In a mini Baja project, for example, the ergonomic bias is present, since any complication in it can cause problems for short and long term, even disturbing the competition performance, therefore, using methods like softwares and appropriate materials, like foams and leg supports, seeks to obtain an effective ergonomic project. This study sought to presented the methods used and the obtained results to ensure the better possible ergonomic project to 2019.

Keywords: Ergonomics; Systems; Baja; Project; Competition. 


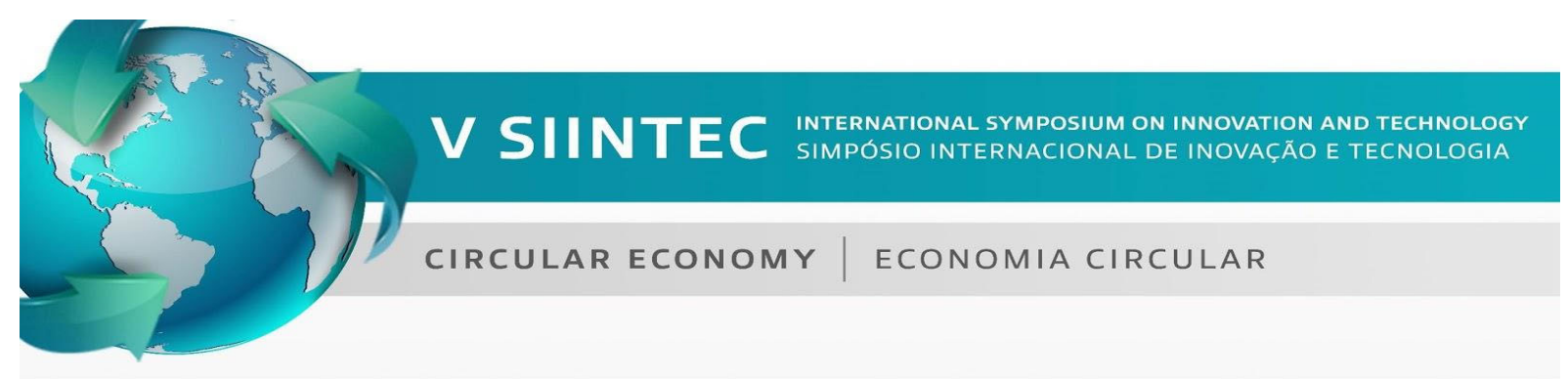

\section{INTRODUÇÃO}

Ergonomia é uma disciplina científica voltada ao entendimento das interações entre os seres humanos e outros elementos ou sistemas, e à aplicação de teorias, princípios, dados e métodos a projetos com o intuito de otimizar o bem-estar humano e o desempenho global do sistema [1].

Para a condução de um veículo, o piloto necessita realizar diversas funções simultaneamente. É preciso manter o foco na pista/trajeto a ser seguido, ficar atento às informações do painel referentes à situação momentânea do veículo, e ter domínio de todos os dispositivos de controle do veículo, tais como pedais e volante. Além disso, o período em que o piloto permanecerá na posição de pilotagem é relevante e deverá ser levado em consideração, buscando evitar todo e qualquer movimento que possa causar estresse, seja ele muscular ou mental, na condução do veículo. Para o estudo em questão, será levado em consideração a ergonomia física e cognitiva.

Segundo [1], a ergonomia física está relacionada com as características da anatomia humana, antropometria, fisiologia e biomecânica. Já a ergonomia cognitiva, refere-se aos processos mentais tais como percepção, memória, raciocínio e resposta motora conforme afetem as interações entre seres humanos e outros elementos de um sistema.

Um protótipo mini baja consiste em um veículo off road que comporta apenas o piloto, desenvolvido e construído por uma equipe de estudantes, tendo como objetivo participar das competições coordenadas pela SAE BRASIL. Durante as competições, o protótipo será submetido a provas de inspeção técnica e conformidade, provas dinâmicas e o enduro de resistência. Dentre as provas, uma específica analisa o conforto da pilotagem do protótipo, sendo utilizada para estudo tanto a ergonomia física quanto a cognitiva.

Portanto, este estudo visa alcançar a posição ideal de pilotagem em um protótipo mini baja, aumento do conforto, segurança e saúde dos seus usuários, através de análises, estudos e experimentos, possibilitando a utilização otimizada do veículo pelo piloto. Em destaque a aplicação de estudos ergonômicos pelo software CATIA, tais como a análise RULA e de provável faixa de visão do piloto, buscando otimizar todo e qualquer ponto para garantir conforto satisfatório ao condutor. 


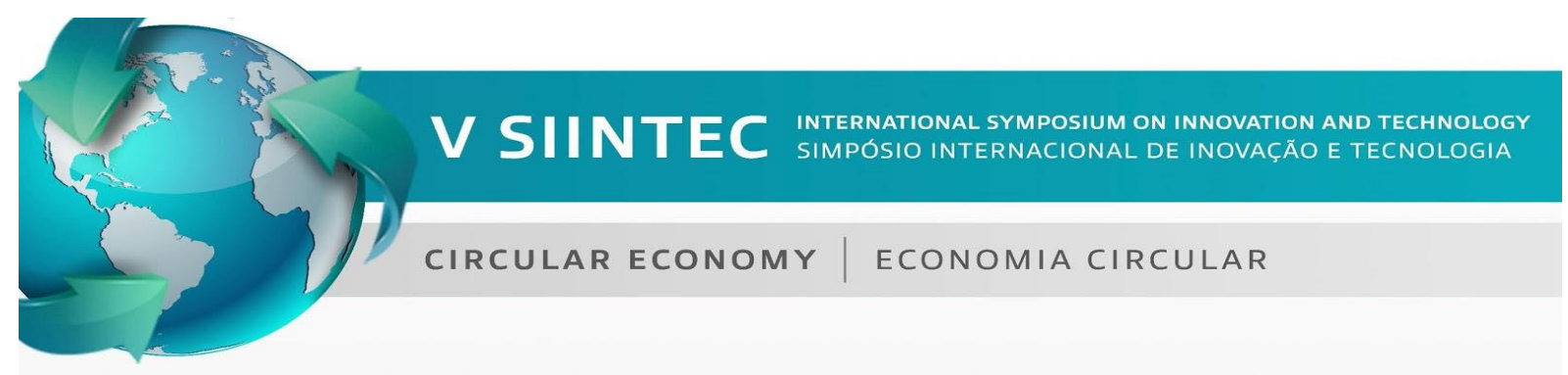

Figura 1: Medidas tomadas como referência

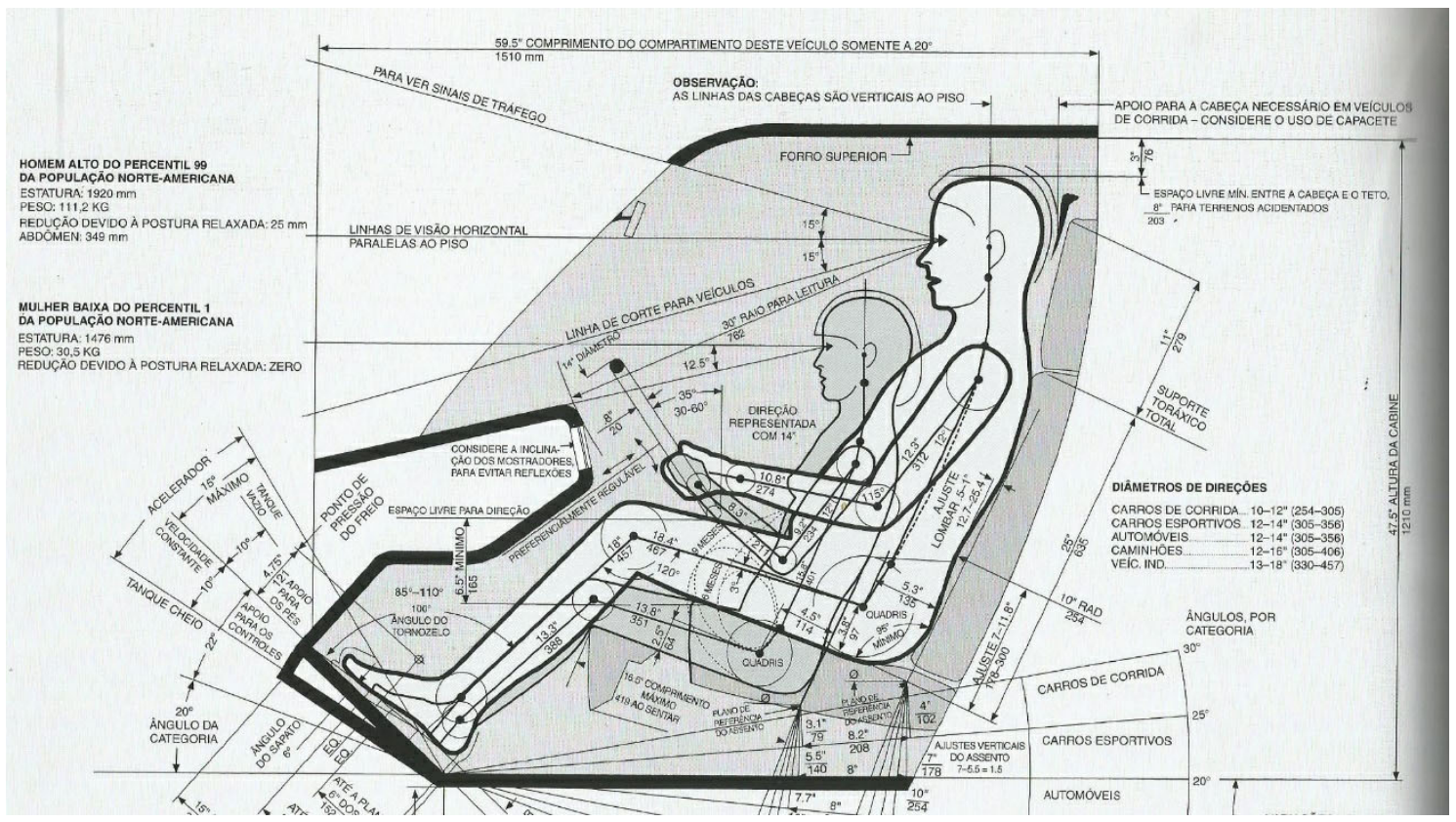

Fonte 1: TILLEY, Alvin R., pág. 72

\section{METODOLOGIA}

Analisando o caso de um protótipo mini baja, têm-se menos controles em relação a um veículo manual de passeio, por exemplo. No caso analisado, o veículo possui apenas dois pedais de controle, um acelerador e um freio; um volante; um botão de emergência, para desligamento do veículo em caso de acidente; retrovisores externos; e um painel de instrumentos. Além disso, a área disponível para o cockpit do piloto é restrita pelo projeto e por [3].

Utilizando como referência bibliográfica [2] buscou-se atingir as medidas definidas pelo autor. Levando em consideração que a norma não abrange as medidas de um mini baja, algumas das dimensões encontradas serão ajustadas em visão a um melhor conforto do piloto.

De acordo com [3], a estrutura do cockpit deverá ser capaz de abrigar pessoas de ambos os sexos, desde o percentil 1 feminino, até o percentil 99 masculino.

Alguns fatores constantes em assento de veículos, que são imprescindíveis para uma posição ergonômica e confortável, [2] são utilizados como referência a fim de aprimorar o projeto de ergonomia já presente no protótipo de 2018, o KOMODO, visando buscar a excelência no protótipo 2019 da equipe. 


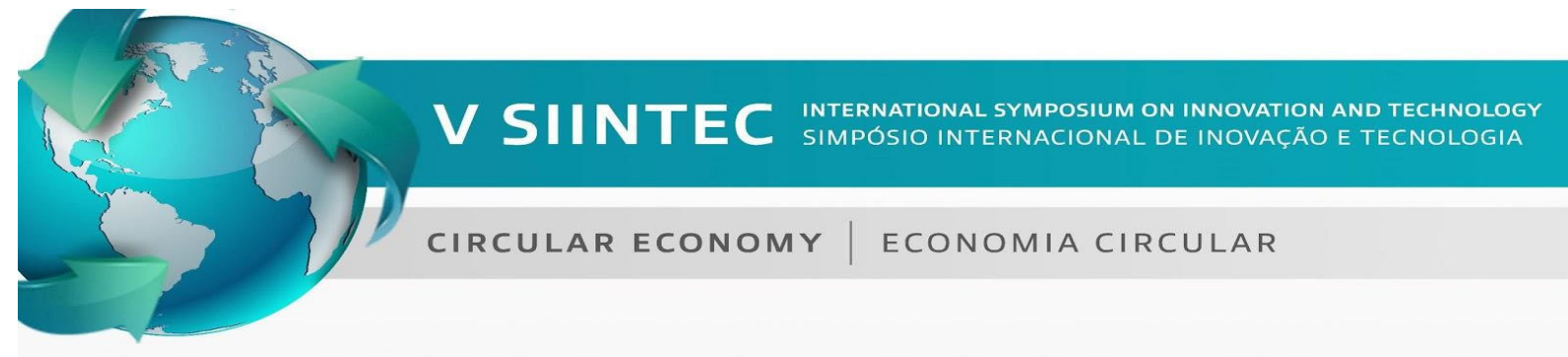

Tabela 1: Medidas ideais [2]

\begin{tabular}{ll}
\hline Membro do corpo & Medida \\
\hline Joelhos & $110^{\circ}-120^{\circ}$ \\
Assento - Encosto & $95^{\circ}$ \\
Perna - Coluna Vertebral & $95^{\circ}-100^{\circ}$ \\
Braço & $115^{\circ}$ \\
Tornozelo & $100^{\circ}$ \\
Braço - Punho & $0^{\circ}-35^{\circ}$ \\
\hline
\end{tabular}

Além dessas medidas, o apoio para a cabeça deverá manter a linha central da cabeça vertical, para uma melhor visão da pista, o deslocamento do pedal de freio deverá estar entre $13 \mathrm{~mm}$ e $64 \mathrm{~mm}$, e o pedal do acelerador de aproximadamente $20^{\circ}$, e o diâmetro ideal de volante é de 14".

Com base nesses dados, foi feito uma fotogrametria, que consiste em analisar distâncias e medições de um objeto por meio de uma fotografia, da posição de um dos pilotos da equipe, que possui $1,75 \mathrm{~m}$ de estatura.

Figura 2: Fotogrametria piloto percentil 75

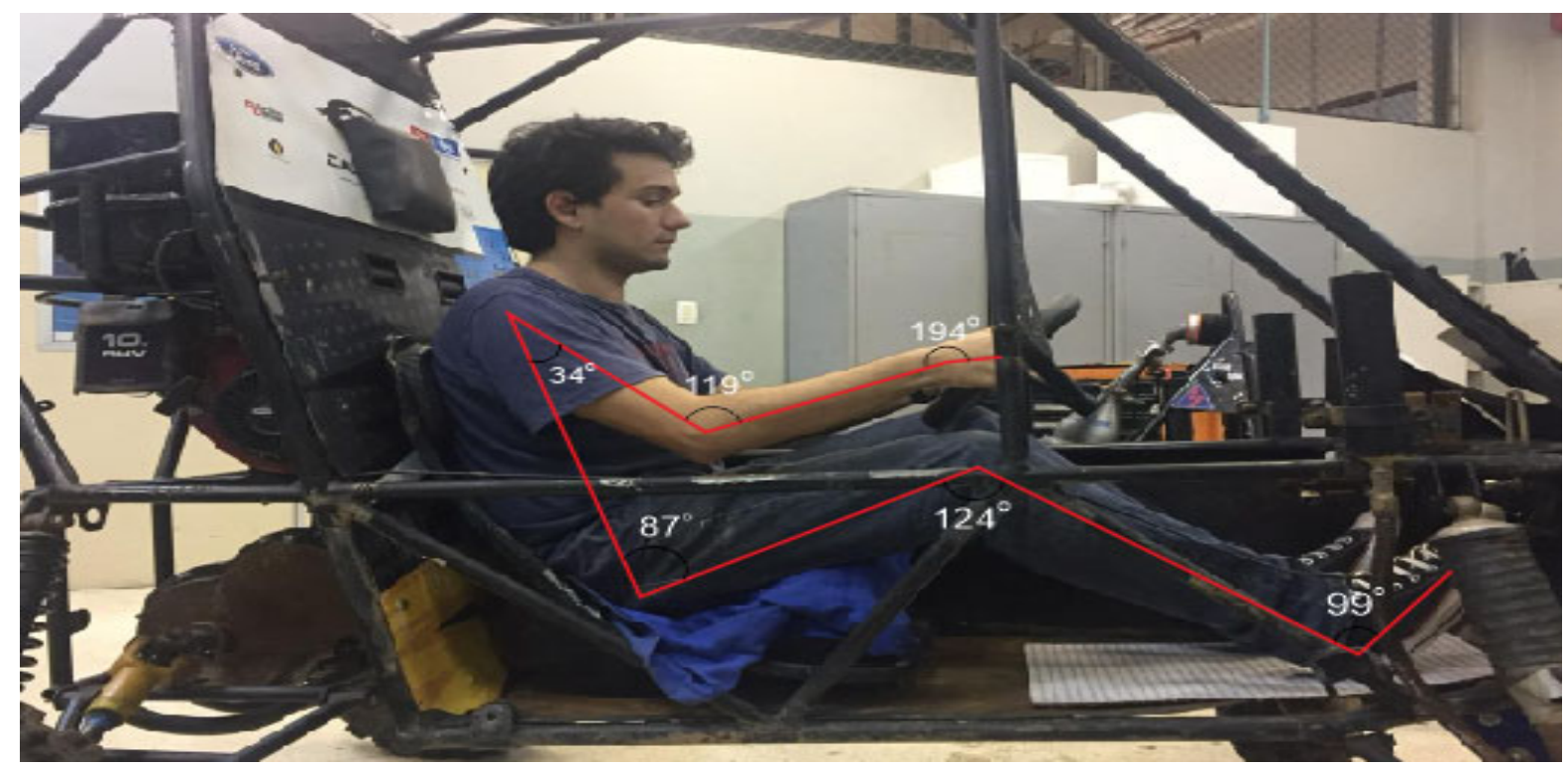

Fonte 2: Própria equipe 


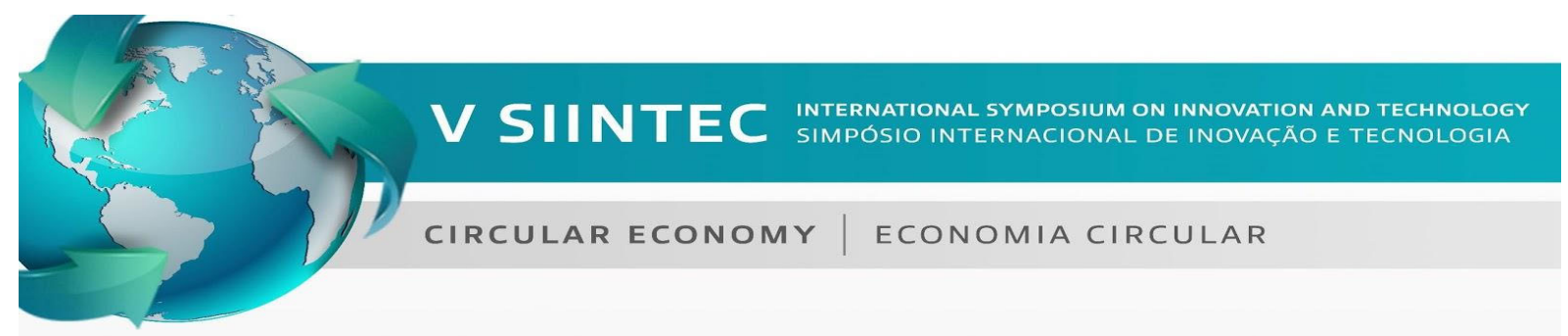

Analisando a figura 2, é possível perceber que, apesar de apresentar valores próximos aos sugeridos, a ergonomia do protótipo 2018 possui alguns pontos que devem ser melhorados. Para se aproximar aos valores apresentados por [2], uma análise no mockup da equipe foi realizada com outro piloto de mesma estatura, e assim realizar as alterações necessárias no banco e estrutura do protótipo.

Figura 3: Fotogrametria no mockup ergonômico

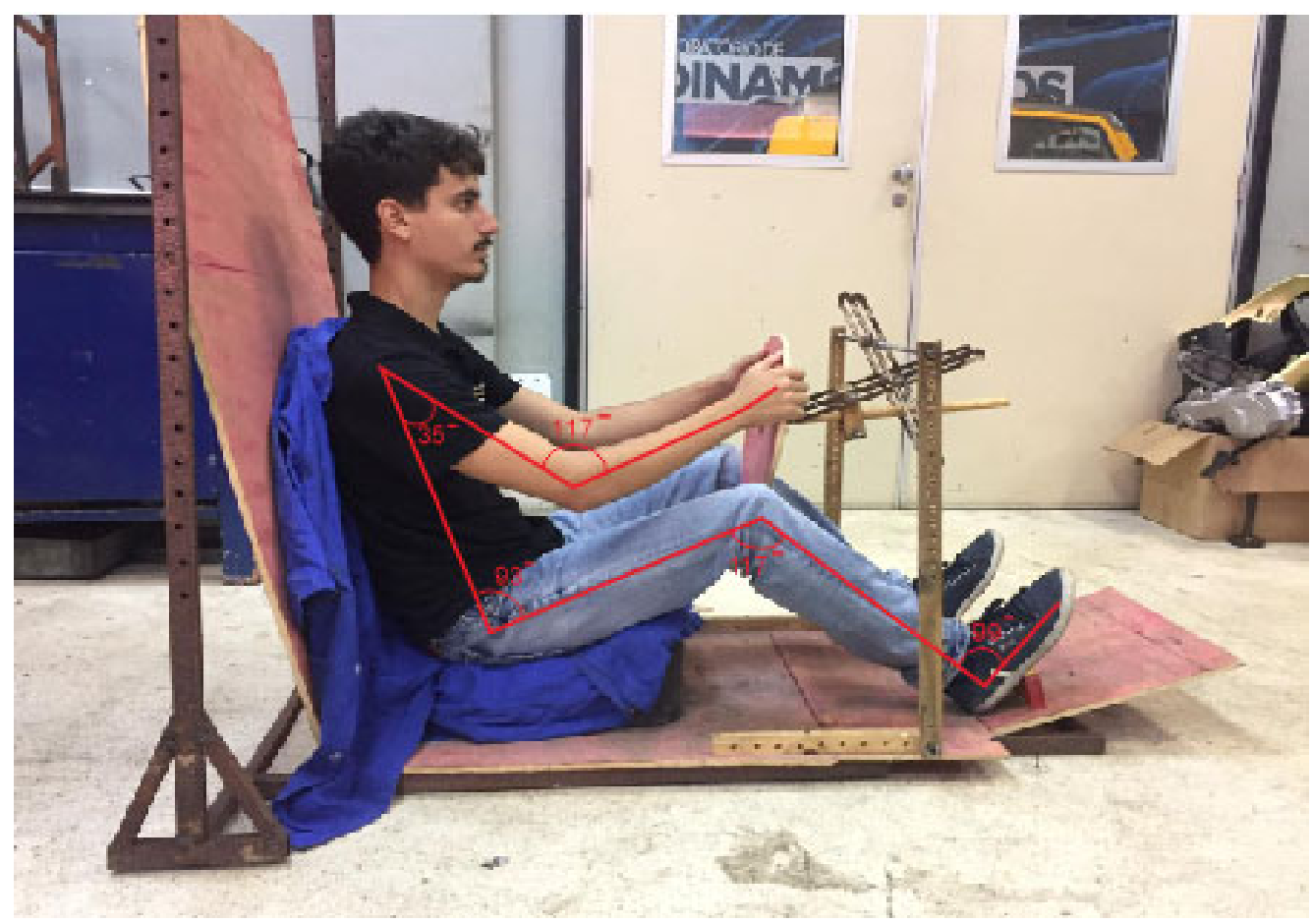

Fonte 3: Própria equipe

Através das medidas obtidas, algumas alterações foram realizadas, tais como redução da espessura do banco e aumento da angulação entre assento e encosto (ver figura 4), ajuste da distância entre o volante e braços do piloto, ajuste da altura e curso dos pedais. Além dessas alterações, foi feito um apoio para a região posterior da coxa no banco do protótipo, a fim de reduzir os esforços realizados pelo piloto para se manter em posição de pilotagem.

Com as alterações realizadas no CAD do banco e da estrutura, foram feitas análises ergonômicas no software CATIA, simulando o físico de pessoas dos percentis 37 feminino, 75 masculino - que consiste no percentil do piloto da equipe - e 99 masculino. Além disso, foi analisado por meio dos métodos RULA (Rapid Upper Limb Assessment) e da visualização da provável faixa de visão do piloto, o quão favorável estava a ergonomia para cada percentil. 


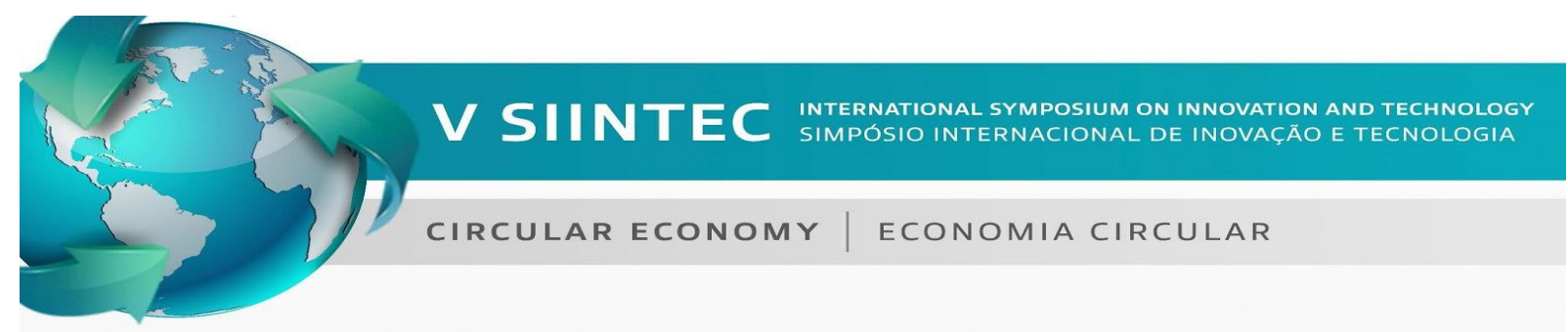

A análise RULA fornece o score da probabilidade de ocorrência de lesão ao condutor em determinada postura, e por meio de uma pontuação final, obtém-se fundamento do quão confiável está a ergonomia.

Tabela 2: Rula Analysis

\begin{tabular}{|c|c|c|}
\hline Pontuação & Nível de Ação & Intervenção \\
\hline 1 ou 2 & 1 & Postura aceitável. \\
\hline 3 ou 4 & 2 & $\begin{array}{l}\text { Deve-se realizar uma observação e podem ser } \\
\text { necessárias mudanças. }\end{array}$ \\
\hline 5 ou 6 & 3 & $\begin{array}{l}\text { Deve-se realizar uma investigação e introduzidas } \\
\text { mudanças. }\end{array}$ \\
\hline 7 & 4 & Devem ser introduzidas mudanças imediatamente. \\
\hline
\end{tabular}

Figura 4: Piloto percentil 99 em posição de pilotagem (esquerda) e visão ao pilotar (direita)

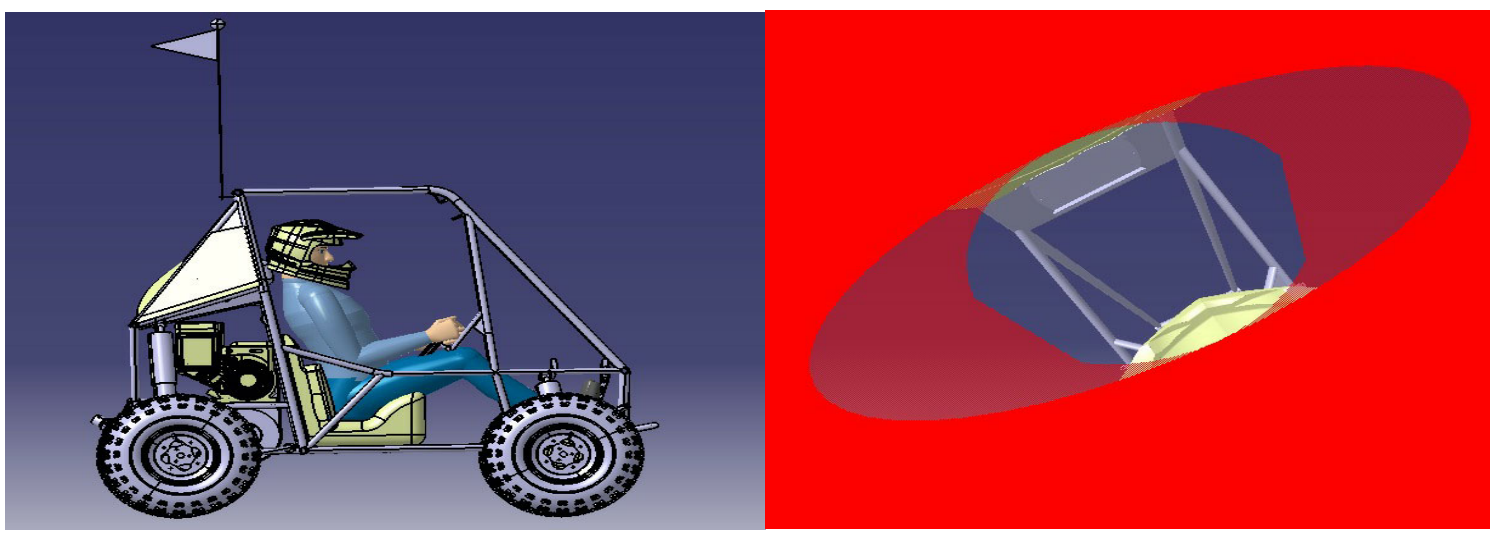

Fonte 4: Própria equipe

Figura 5: Piloto percentil 37 em posição de pilotagem (esquerda) e visão ao pilotar (direita)

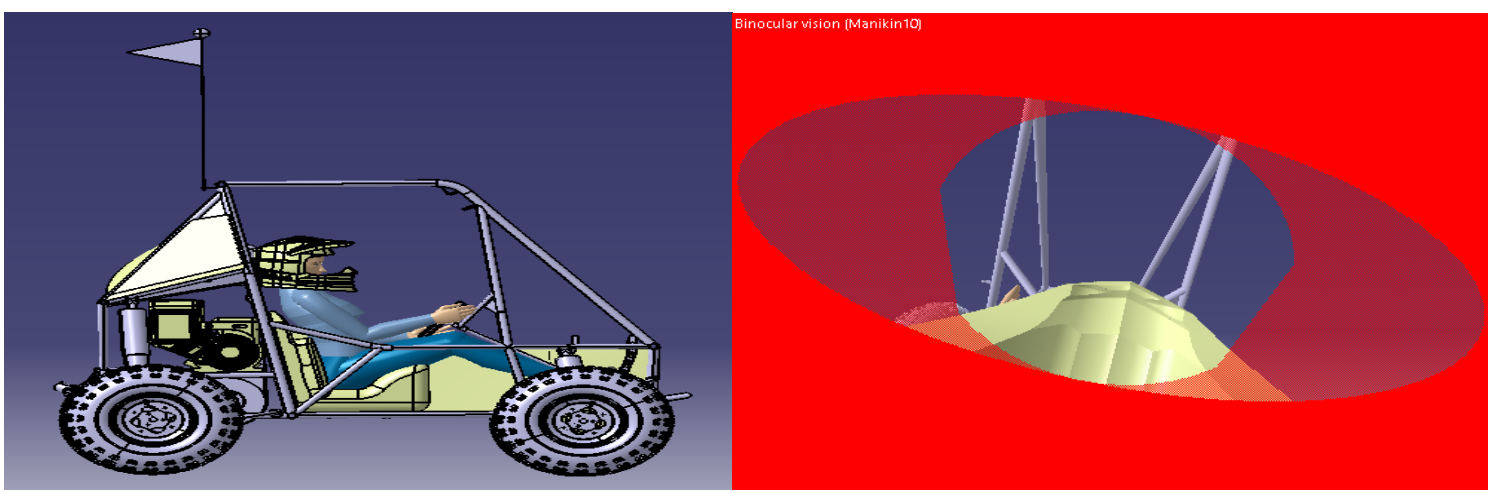

Fonte 5: Própria equipe 


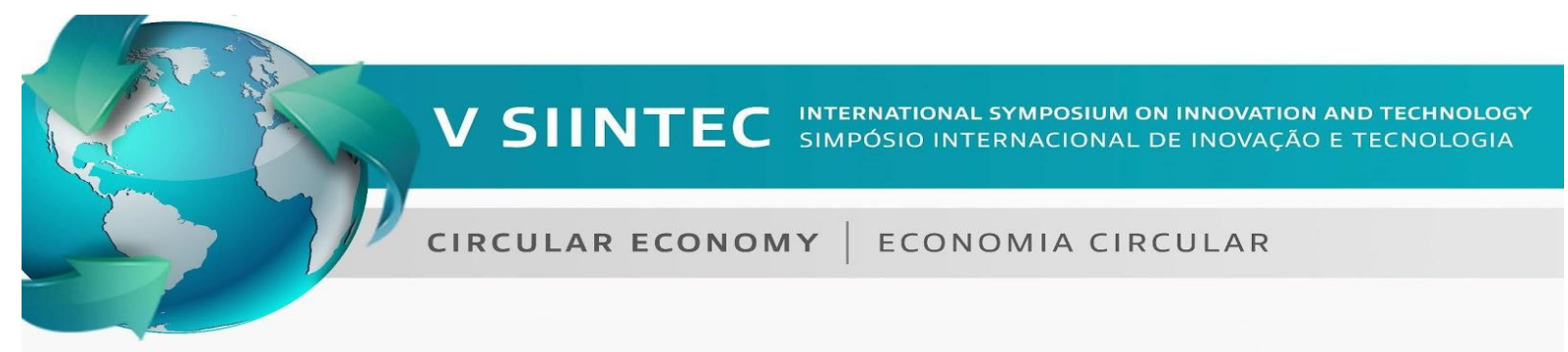

Figura 6: Piloto percentil 75 em posição de pilotagem (esquerda) e visão ao pilotar (direita)

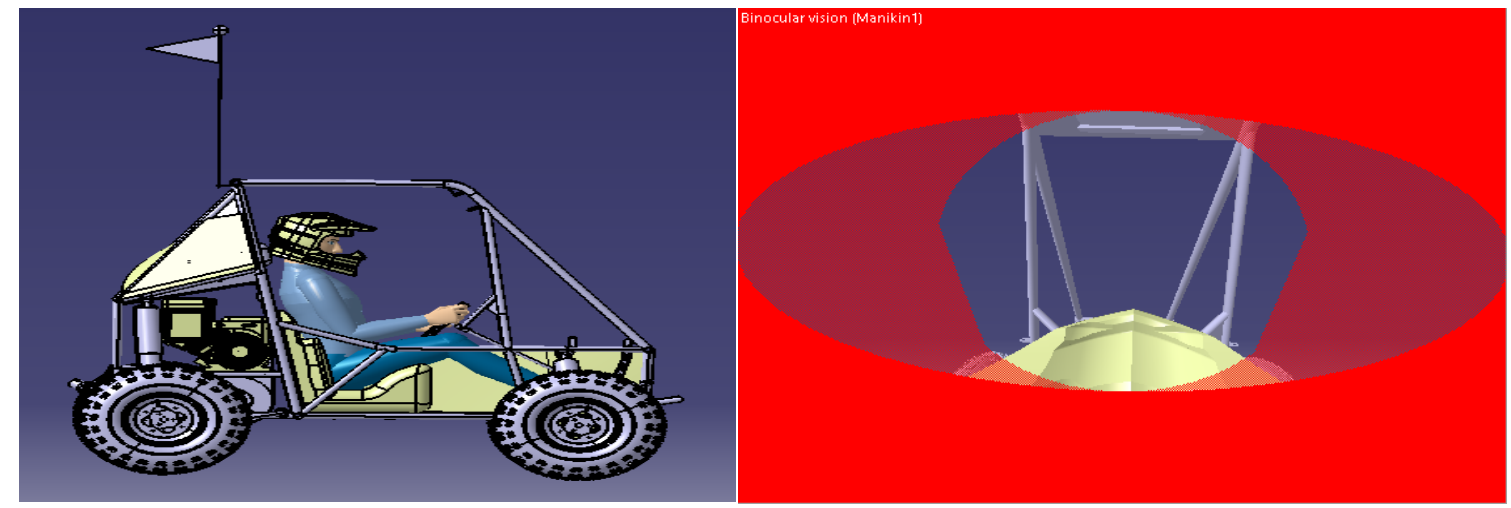

Fonte 3: Própria equipe

\section{RESULTADOS E DISCUSSÕES}

De acordo com as análises realizadas, o protótipo é capaz de abrigar, respeitando uma ergonomia física e visual suficiente, pilotos do percentil 37 feminino ao percentil 99 masculino. Foi possível perceber que, apesar das diferentes alturas dos pilotos, é possível obter uma visão completa da pista. Além disso, realizou-se também uma análise da ergonomia visual no instante em que o piloto olha para o painel de instrumentos, localizado na porção superior da estrutura, apresentando um resultado satisfatório, como mostra a tabela 2.

Tabela 3: Inclinação da cabeça necessária para leitura do painel

\begin{tabular}{lc}
\hline \multicolumn{1}{c}{ Piloto } & Inclinação \\
\hline Percentil 99 Masculino & $1^{\circ}$ \\
Percentil 75 Masculino & $3,5^{\circ}$ \\
Percentil 37 Feminino & $6^{\circ}$ \\
\hline
\end{tabular}

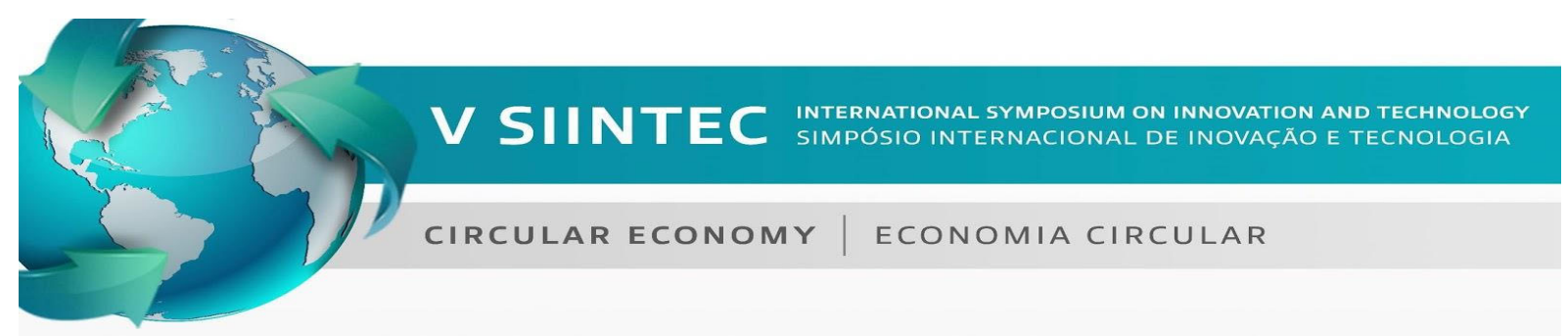


Além disso, devido ao resultado da análise RULA, as quais para todos os percentis obteve-se nível de ação 2, a situação ergonômica foi considerada aceitável, levando em conta as condições de pilotagem e a utilização de percentis dos extremos inferior e superior para a realização da análise, o que implica na pior situação de pilotagem possível.

Tabela 3: Pontuação da análise RULA

\begin{tabular}{lc}
\hline \multicolumn{1}{c}{ Piloto } & Pontuação \\
\hline Percentil 99 Masculino & 3 \\
Percentil 75 Masculino & 3 \\
Percentil 37 Feminino & 4 \\
\hline
\end{tabular}

\section{CONSIDERAÇÕES FINAIS}

Através das análises obtidas pelas simulações ergonômicas realizadas com o software CATIA e o mockup ergonômico, foi possível verificar a eficácia da ergonomia projetada para o protótipo 2019. Apesar da pontuação maior obtida no percentil 37 feminino - observando os dados da Tabela 3 - o resultado foi satisfatório, uma vez que o a média dos pilotos da equipe corresponde ao percentil 75 , e este apresentou uma pontuação suficientemente boa.

Além disso, tomou-se conhecimento de aspectos para serem melhorados para o projeto 2020, tais como a modificação do posicionamento dos pedais de aceleração e freio para que pessoas com percentis menores possam conduzir o veículo com maior conforto e menores riscos de lesões.

\section{REFERÊNCIAS}

'Associação Brasileira de Ergonomia. O que é ergonomia. Disponível em: http://www.abergo.org.br/internas.php?pg=o_que_e_ergonomia. Acesso em: 28 de julho de 2019.

${ }^{2}$ TILlEY, Alvin R.; ASSOCIATES, Henry Dreyfuss. AS MEDIDAS DO HOMEM E DA MULHER: FATORES HUMANOS EM DESIGN. Bookman Companhia Ed, 2005. 104 p.

${ }^{3}$ SAE BRASIL. RATBSB 2: REGULAMENTO ADMINISTRATIVO E TÉCNICO BAJA SAE BRASIL. 2 ed. S.1.: Baja Sae Brasil, 2018.137p.

${ }^{4}$ SANTOS, Adriana Borges dos. ESTUDO ERGONÔMICO DO VEÍCULO BAJA DO CENTRO UNIVERSITÁRIO UNIVATES.2015. 64 f. TCC (Graduação) - Curso de Engenharia de Produção, Centro Universitário UNIVATES, Lajeado, 2015.

${ }^{5}$ International Ergonomics Association. Definition and Domains of Ergonomics. Disponível em: https://www.iea.cc/whats/index.html. Acesso em: 28 de julho de 2019. 